
PNQM31

\title{
AVALIAÇÃO DA ATIVIDADE LARVICIDA DE EXTRATOS AQUOSOS DE CAULES DE CORDYLINE FRUTICOSA (ASPARAGACEAE) SOBRE O AEDES AEGYPTI (DIPTERA: CULICIDAE)
}

\author{
C. M. T. C. CAMPOS ${ }^{1,}$ C. R. F. NETA ${ }^{2}$, R. C. D. da CRUZ ${ }^{2}$, R. J. O. $\operatorname{COSTA}^{2,}$ K. S. \\ CARVALHO ${ }^{3}$ e I. A. de SOUZA $^{2}$ \\ ${ }^{1}$ Universidade Federal de Pernambuco, Centro de Biociências, Departamento de Antibióticos \\ ${ }^{2}$ Universidade Federal de Pernambuco, Centro de Ciências da Saúde, Departamento de \\ Antibióticos \\ ${ }^{3}$ Instituto Aggeu Magalhães (FIOCRUZ, PE)
}

E-mail para contato: cleofigueiredo012@gmail.com

\begin{abstract}
RESUMO - O uso de plantas para fins medicinais e inseticidas sempre foram bastante estudados. Nesses últimos anos, a busca por inseticidas naturais para o controle, principalmente, do Aedes aegypti, tem crescido cada vez mais. Isso se dá porque as plantas possuem substâncias bioativas as quais as tornam importantes na produção desses inseticidas botânicos, Nesse sentido, objetivou-se avaliar os extratos aquosos de caules de Cordyline fruticosa sobre as larvas de Ae. Aegypti. Foram avaliados os extratos obtidos por maceração, infusão e decocção. Para a realização dos bioensaios foram utilizadas 30 larvas de terceiro e quarto instar por repetição, as quais foram expostas a concentração de $100 \%(\mathrm{v} / \mathrm{v})$ dos extratos. Em cada repetição foi utilizado $30 \mathrm{~mL}$ dos extratos e as larvas foram submetidas em contato com os extratos por um período de 24 horas. Foi possível relatar que no periodo de 24 horas não ouve mortalidade larval. Dessa forma, os extratos aquosos obtidos por maceração, infusão e decocção não apresentam efeito tóxico sobre as larvas de terceiro e quarto instar de Ae. aegypti.
\end{abstract}

Palavras-chave: Inseticidas naturais. Bioensaios. Vetores

\begin{abstract}
The use of plants for medicinal purposes and insecticides have always been well studied. In recent years, the search for natural insecticides for the control, mainly, of Aedes aegypti, has grown more and more. This is because the plants have bioactive substances which make them important in the production of these botanical insecticides. In this sense, the objective was to evaluate the aqueous extracts of stems of Cordyline fruticosa on the larvae of Ae. Aegypti. The extracts obtained by maceration, infusion and decoction were evaluated. For the bioassay, 30 larvae of third and fourth instar were used per repetition, which were exposed to the concentration of $100 \%(\mathrm{v} / \mathrm{v})$ of the extracts. In each replicate $30 \mathrm{~mL}$ of the extracts were used and the larvae were submitted to contact with the extracts for a period of 24 hours. It was possible to report that in the 24 hour period it does not
\end{abstract}


hear larval mortality. Thus, aqueous extracts obtained by maceration, infusion and decoction do not present toxic effect on third and fourth instar larvae of Ae. aegypti. Keywords: Natural insecticides. Bioassays. Vectors.

\section{INTRODUÇÃO}

Aedes aegypti (Diptera: Culicidae), é um mosquito originário da África, e se tornou antropofílico, pois se habituou ao ambiente urbano. Esse processo de adaptação ao meio urbano fez com que tivesse maior facilidade para se reproduzir e proliferar nas cidades (BARRETO e TEXEIRA, 2008; DUARTE et al., 2013). Esse vetor é o principal responsável por transmitir doenças como a febre amarela urbana, dengue, febre chikungunya e a síndrome congênita do vírus zika (PICINATO et al., 2015).

Dentre essas doenças destaca-se a dengue, a qual é considerada uma das principais doenças virais transmitida pelo Ae. aegypti, e é também a mais comum arbovirose no mundo. Essa doença é manifestada em mais de 100 países atingindo mais de 2,5 bilhões de pessoas que vivem em áreas urbanas, periurbanas e rurais dos trópicos e subtrópicos (BRAGA e VALLE, 2007). Em 2002, foi registrada uma pandemia do vírus da dengue no continente americano, na qual 69 nações americanas foram atingidas (BARRETO e TEXEIRA, 2008).

De acordo com Oliveira et al. (2008), diversas plantas são consideradas eficazes para diversas doenças, a utilização desses vegetais é bastante incidente no Brasil, o que se deve principalmente a biodiversidade da flora brasileira. O Brasil é um dos países com a maior biodiversidade do planeta e em seu extenso território existem, aproximadamente, $20 \%$ das 250.000 espécies botânicas que compõem a flora mundial. Dentre esta extensa flora brasileira encontra-se presente Cordyline fruticosa.

Segundo a classificação atual Cordyline fruticosa é uma espécie pertencente ao gênero Cordyline, da família Asparagaceae. No entanto ela já foi enquadrada em diversas famílias. Uma característica do caule dessa planta é que eles são aéreos, ereto, lenhoso e com ramificação simpodial (SASAKI, 2015). No âmbito medicinal, as folhas desse vegetal já são comumente utilizadas devido sua ação antinociceptiva, vale resaltar, que essa planta apresenta grande diversidade de compostos ativos como saponinas e flavonoides, as quais são responsáveis pela sua propriedade medicinal (FOUEDJOU et al., 20014). Assim, as substâncias ativas dessa planta também podem apresentar atividade inseticida sobre o Ae. aegypti. Dentro desse contexto, buscou-se avaliar o potencial dos extratos aquosos obtidos de caules de Cordyline fruticosa sobre larvas do terceiro e quarto instar de Ae. aegypti.

\section{MATERIAIS E MÉTODOS}

Para o experimento utilizou-se caules frescos de Cordyline fruticosa através dos seguintes extratos aquosos: maceração, infusão e decocção. Para obtenção dos extratos, os caules inicialmente foram coletados, lavados em água corrente e pesados. Posteriormente, procedeu-se a moagem dos caules através de um triturador mecânico e, em seguida realizou-se a extração do material vegetal. Para obtenção dos extratos aquosos foram utilizados $100 \mathrm{~g}$ de caule moído para 1L de água destilada, na maceração os caules ficaram submersos em água, a uma temperatura ambiente $\left(26^{\circ} \mathrm{C}\right)$ por 3 horas; na infusão a água em ebulição $\left(100^{\circ} \mathrm{C}\right)$ foi vertida sobre os caules por 30 minutos e por último na decocção, os caules ficaram diretamente na água em ebulição $\left(100{ }^{\circ} \mathrm{C}\right)$ por 15 minutos. 
Todas as extrações foram realizadas por extrações parcialmente dinâmicas. Para a realização do ensaio larvicida utilizou-se os extratos aquosos na concentração de $100 \%$ $(\mathrm{v} / \mathrm{v})$, com cinco repetições por tratamento. Foram utilizadas 150 larvas por tratamento, com 30 larvas por repetição e o grupo controle, no qual se utilizou água destilada. Em cada repetição foi utilizado $30 \mathrm{~mL}$ dos extratos aquosos e as larvas foram submetidas em contato por um período de 24 horas. A partir do início do experimento as larvas foram observadas em 1/2, 1, 2, 4, 8, 16, 24 horas. As larvas de terceiro e quarto instar de Ae. Aegypti utilizadas para realização do bioensaio foram oriundas de uma colônia estabelecida no Laboratório de Pesquisa de Toxicologia do Departamento de Antibióticos da Universidade Federal de Pernambuco-UFPE, a partir de ovos da linhagem Rockefeller, cedidos pelo Insetário do Instituto Aggeu Magalhães (FIOCRUZ- PE). Para a realização dos ensaios biológicos, seguiu a metodologia adaptada de World Health Organization (1970).

\section{RESULTADOS E DISCUSSÃO}

Os extratos aquosos (maceração, infusão e decocção) proveniente de caules frescos de Cordyline fruticosa, no período de 24 horas não ocasionou mortalidade larval, o que demonstra, que o extrato aquoso não apresenta toxicidade sobre as larvas de $A e$. aegypti. A ausência de toxicidade pode ter ocorrido em função da ausência de secagem dos caules de Cordyline fruticosa, visto que, a temperatura ocasionada pela secagem, poderá facilitar a liberação de compostos ativos. Estudos realizados por Cruz et al., (2015), com extratos aquosos e hidrolato de folhas frescas de Croton argyrophyllus sobre larvas de $A$ e. aegypti, também não detectaram atividade inseticida.

De acordo com Jacobi et al., (1991), a secagem de materiais botânicos, faz com que a integridade das membranas de células vegetais detentoras de substâncias bioativas são rompidas, facilitando assim, a liberação dos metabólitos secundários nos extratos, como exemplo as cumarinas, taninos e flavonoides.

\section{CONCLUSÃO}

Os extratos aquosos obtidos pelos métodos de maceração, infusão e decocção provenientes de caules frescos de Cordyline fruticosa não demonstraram toxicidade sobre as larvas de Ae. aegypti. Nesse sentido, faz-se necessário a realização de novos ensaios biológicos, para detectar uma possível atividade larvicida de caules secos deste vegetal.

\section{REFERÊNCIAS}

BARRETO, M. L.; TEIXEIRA, M. G. Dengue no Brasil: situação epidemiológica e contribuição para uma agenda de pesquisa. Rev. Est. Avan., v. 22, n. 64, p. 53-72, 2008.

BRAGA, I.; VALLE, D. Aedes aegypti: inseticidas, mecanismos de ação e resistência. Epid. Serv. Saúd., v. 16, n. 4, p. 279-293, 2007.

CRUZ, R. C. D.; CARVALHO, K. S.; CUNHA, S. L. S.; GUALBERTO, S. A. avaliação da atividade larvicida de extratos aquosos e do hidrolato obtidos das folhas de Croton argyrophyllus sobre o Aedes aegypti. Rev. Enciclop. Biosf., v.11, n. 21 p.2835, 2015. 
DUARTE, E. H.; PEREIRA, J.; OLIVEIRA, H.; LIMA, H. S.; PEREZ, A.; PILE, E. Aedes (Stegomyia) aegypti em algumas ilhas de Cabo Verde: Tipologia dos criadouros e sua relação com a presença larval. Rev. Arqui. Instit. Biológ., v. 80, n. 3, p. 359-362, 2013.

FOUEDJOU, R. T.; TEPONNO, R. B.; QUASSINTI, L.; BRAMUCCI, M.; PETRELLI, D.; VITALI, L. A.; BARBONI, L. Steroidal saponins from the leaves of Cordyline fruticosa and their cytotoxic and antimicrobial activity. Phytochem. Lett., v. 7, p. 62-68, 2014.

JACOBI, U. S.; FERREIRA, A. G. Efeitos alelopáticos de Mimosa bimucronata sobre espécies cultivadas. Rev. Pesq. Agropec. Bras., v. 26, n. 7, p. 935-943, 1991.

OLIVEIRA, C. C.; CABRINI, D. A.; SANTOS, E. P.; MARQUES, M. C. A, BUCHI, D. F. Canova medication and medical plants in South of Brazil. In: Pretorius R, editor. Trends and Developments in Ethnopharmacology. Rev. Research. Signpost., v. 1, n. 3, p. 111-29, 2008.

PICINATO, M. A. D. C.; GRISOliO, A. P. R.; CASELANI, K.; NUNES, J. O. R.; CARVALHO, A. A. B.; FERRAUDO, A. S. Dengue: uma visão sobre o vetor urbano Aedes aegypti e a difícil interface do seu controle. Ver. Vet. Foco., v. 13, n. 1, p. 09-25, 2015. 2015.

SASAKI, K. L. M. Estudos Morfoanatômicos em Órgãos vegetativos de Cordyline fruticosa (L.) Chevalier, C. australis Kunth \& Bouché. 2015. 57f. Dissertação de Mestrado - Instituto de Biociências da Universidade de São Paulo. Departamento de Botânica. São Paulo. 2015.

WORLD HEALTH ORGANIZATION (WHO). International drug monitoring-the role of the hospital. A WHO Report. Drug Intelligence and Clinical Pharmacy, v. 4, p. 101-110, 1970.

\section{AGRADECIMENTOS}

À Universidade Federal de Pernambuco- UFPE e ao Instituto Aggeu Magalhães (FIOCRUZ - PE). 